\title{
¿Piensan lo mismo ciudadanos y partidos sobre la sátira política? La diferente percepción en el caso de un programa televisivo
}

\author{
Carme Ferré PAVIA \\ Universidad Autónoma de Barcelona (UAB) \\ Carme.Ferre@uab.cat \\ Marçal SinTes Olivella \\ Universidad Autónoma de Barcelona (UAB) \\ marcalSO@blanquerna.url.edu \\ Catalina GAYÀ MORLÀ \\ Universidad Autónoma de Barcelona (UAB) \\ Catalina.Gaya@uab.cat
}

Recibido: $25 / 05 / 2012$

Aceptado: 10/12/2012

\begin{abstract}
Resumen
Este estudio aborda el efecto de la sátira televisiva en su reflejo de la vida política. Aporta una mirada nueva: la diferente percepción de la ciudadanía y de la clase política sobre la capacidad de generar cambios emotivos y de opinión de la información parodiada por el programa Polònia. A través de los datos obtenidos con tres herramientas metodológicas (encuesta aleatoria, grupo de discusión y entrevistas) se concluye que la clase política valora el retrato de la vida política como fiel. Los ciudadanos de la muestra niegan, sin embargo, que este pueda aumentar su interés por la política o genere un cambio de opinión.

Palabras clave: percepción mediática de la política, sátira política, infosátira, estudios de recepción, Polònia

\section{Do Political Parties and Members of the Public Think about Political Satire in the Same Way? Differences in Perception with Regards to a Television Programme}

\begin{abstract}
This study addresses the effectiveness of television satire in reflecting political life. It looks at the subject in a new way: the general public and those involved in politics have different perceptions about the ability of a Polònia parody to produce both emotional feelings and changes of opinion. Three methodological tools (a random survey, a focus group and interviews) were used to obtain data. It was concluded that those involved with politics feel that the programme's portrayal of political life is accurate. However, members of the general public do not feel that it increases their interest in politics or that it can provoke a change in their opinion.
\end{abstract}

Keywords: mediatic perception of politics, political satire, infosatire, reception studies, Polònia

\section{Referencia normalizada}

FERRÉ PAVIA, Carme; SINTES OLIVELLA, Marçal; y GAYÀ MORLÀ, Catalina; (2013): “_Piensan lo mismo ciudadanos y partidos sobre la sátira política? La diferente percepción en el caso de un programa televisivo". Estudios sobre el mensaje periodístico. Vol. 19, Núm. 1, págs.: 383-402. Madrid, Servicio de Publicaciones de la Universidad Complutense.

Sumario: 1. Introducción. 2. Marco teórico. 3. Objetivos de investigación. 4. Diseño metodológico; 4.1. Encuesta aleatoria; 4.2. Grupo de discusión; 4.3. Entrevistas focalizadas. 5. Resultados de investigación; 5.1. La imagen de las figuras políticas; 5.1.1. Divulgación de las figuras políticas; 5.1.2. Humanización 
de las figuras políticas; 5.1.3. Cambios de actitud en la audiencia; 5.2. Retrato de la vida política; 5.3. Interés por la política y participación; 5.3.1. Generación de interés por la política; 5.3.2. Capacidad para generar cambios de opinión; 5.3.3. Participación e incidencia electoral del infotainment. 6. Conclusiones. 7. Referencias bibliográficas. 8. Anexo: gráficos.

\section{Introducción ${ }^{1}$}

El estudio de la interacción entre los medios de comunicación y sus audiencias y de cómo éstas interpretan los mensajes mediáticos y los incorporan a su conciencia cuenta con una larga tradición académica. El presente trabajo se inscribe en este campo, centrándose en la influencia de la infosátira. ${ }^{2}$ El objetivo es reflexionar sobre los efectos en las audiencias de este subgénero del infoentreteniento y, además, comparar cómo espectadores y clase política evalúan el vínculo con un determinado espacio televisivo. Partimos de la siguiente pregunta de investigación: ¿Perciben de la misma manera los efectos de la sátira política la ciudadanía y la clase política?

Para abordar los efectos del infotaiment en la ciudadanía se han combinado diferentes herramientas metodológicas: una encuesta cuyo universo es de 1.241 personas; un grupo de discusión de seis personas, y una serie de seis de entrevistas focalizadas a responsables de comunicación de los partidos políticos del arco parlamentario catalán. Los resultados de la encuesta y del grupo de discusión nos informan de cómo el espectador interpreta su relación con un programa de sátira política de gran audiencia, el programa Polònia del canal autonómico catalán TV3.

En el trasfondo del estudio de los efectos de los mensajes mediáticos de carácter político se encuentra el debate, recurrente en las últimas décadas, en torno a la contribución de tales contenidos al fenómeno de la llamada desafección política, que se manifiesta tanto en la baja valoración que reciben los políticos en los sondeos de opinión como en los altos índices de abstención electoral.

Las conclusiones del presente trabajo se fundamentan en la comparación de la percepción que audiencia y expertos de los partidos hacen de la representación de la vida política que emana del programa Polònia. Ciudadanía y spin-doctors no siempre coinciden al valorar cómo los contenidos de la infosátira pueden influir en la creación de opiniones y actitudes.

Desde sus inicios, Polònia -cuyo nombre alude irónicamente al apelativo de polacos con el que a veces se califica con menosprecio a los catalanes- ha contado con el favor del público, alcanzando audiencias muy superiores a los programas televisivos de información y debate político considerados serios. Tiene una media de 673.000 espectadores por programa y, durante cinco temporadas, ha alcanzado de media un share del $23,5 \%$.

1 Nereida CARrillo PÉrez (nereida.carrillo@gmail.com), de la Universidad Autónoma de Barcelona (UAB), ha sido asistente de investigación de este estudio original.

2 Podríamos considerar Polònia un programa de infosátira, según la definición de Valhondo (2007), ya que propone un tratamiento paródico de la información política con una referencia subyacente al cinismo de los políticos. Polònia, además, tiene características distintivas propias como son la serialización, la creación de personajes que adquieren personalidad propia y la producción artística. 
El programa de sátira política ha conseguido convertirse en un referente televisivo $\mathrm{y}$, en cierto modo, en un relevante fenómeno de la cultura popular catalana, amén de erigirse en permanente objeto de debate y polémica entre políticos, periodistas e investigadores. Ya desde su nacimiento, ha tenido tanto éxito que sus responsables clonaron la fórmula y crearon Crakòvia, dedicado al mundo del fútbol.

Polònia empezó a emitirse en el primer canal -TV3- de Televisió de Catalunya en febrero de 2006, es decir, durante los últimos meses en el poder del Gobierno de coalición de las izquierdas catalanas formado tras los comicios de 2003 y presidido por Pasqual Maragall. El 1 de noviembre de 2006 se celebraron elecciones autonómicas anticipadas en Cataluña y se reeditó el llamado tripartito, pero en esta ocasión bajo la dirección de José Montilla. A este gobierno le sucedería cuatro años después un ejecutivo de CiU presidido por Artur Mas. El programa ha coincidido con las dos legislaturas de gobiernos presididos por José Luis Rodríguez Zapatero. En el momento de escribir este artículo, Polònia continúa su andadura con un nuevo ejecutivo presidido por el popular Mariano Rajoy.

\section{Marco teórico}

El estudio de los efectos de los contenidos de carácter político tiene un largo e intenso recorrido. En sus antecedentes destacan las aportaciones de Walter Lippmann en su Public Opinion. Son muchas las obras que, desde diferentes perspectivas y a lo largo de toda la historia de la investigación comunicativa, han alimentado el debate sobre los efectos perniciosos de los mensajes de los media.

Desde los años sesenta y setenta, muchos expertos han dado por sentado el vínculo causal entre unos medios a los que se acusa de no cumplir adecuadamente sus funciones democráticas y el distanciamiento y la actitud negativa de los ciudadanos respecto a sus gobiernos y los políticos en general. Así, entre los críticos, cabe citar a los hermanos Lang (1966), Robinson (1976), Postman (1985), Sabato (1991), Patterson (1993), Schudson (1995), Cappella y Jamieson (1997), Putnam (2000) y Lloyd (2004) o Martínez (2006), entre otros autores.

Robinson (1976) reflexiona sobre cómo la videomalaise 3 puede disminuir el apoyo específico a líderes, gobiernos y políticas en particular, de una forma similar a cómo, por ejemplo, una cobertura extensa de una serie de crímenes violentos puede hacer crecer el apoyo a la pena de muerte. Otros autores, como Pippa Norris (2000), señalan que no está claro que una muy agresiva o, directamente, mala praxis mediática ponga en jaque el compromiso social de la ciudadanía o su apoyo de fondo al sistema político democrático.

Las aportaciones de Moy, Xenos y Hess (2005) amplían el alcance de los diferentes efectos que el infotainment ejercería. Dichos autores consideran que programas de este tipo pueden incrementar el compromiso político. Defienden el efecto de im-

3 El término videomalaise se utiliza para en referencia a la disminución de la confianza en políticos y gobernantes causada hipotéticamente por la hegemonía de la televisión como medio a través del cual los ciudadanos reciben información sobre asuntos políticos. 
plicación que generan a través del debate, aunque matizan que dichos efectos varían según el tipo de audiencia.

Otro sector de expertos afirma que los programas de infotainment acercan de una manera u otra la política a los ciudadanos, generan más comunicación interpersonal sobre temas políticos y contribuyen así a la vida política. Algunos incluso hablan de “democratización" (Brants, 1998; McNair, 2006; Thussu, 2007). Jones y Baym son claros al respecto:

"As we traverse the wide range of parody programs produced in and for differing governmental structures and media systems, it becomes clear that parody has also become an increasingly central mechanism for public engagement with the state, and the formal realm of legislative and electoral politics." (Jones y Baym, 2012: 10)

También Rodríguez Virgili, López-Escobar y Tolsa (2011) han concluido que los ciudadanos que hacen un uso más intensivo de los medios tienden a mantener actitudes menos negativas sobre los políticos y la política.

Polònia ha sido desde sus inicios objeto de continuo debate y polémica, tanto ciudadana como política. El 27 de marzo del 2008, el diario Avui planteó en una encuesta en línea la siguiente pregunta: “¿Creéis que Polonia de TV3 ha influido en los resultados electorales?" (en el contexto de las elecciones generales del 10 de marzo). A las 19.04 horas habían votado 3.416 personas: un 55\% negaba esta influencia; un $22 \%$ afirmaba que había afectado "mucho", y un $23 \%$ que "sí, pero poco". El mismo año el exconsejero del gobierno de la Generalitat Josep Maria Vallès escribía:

"Creo que algunos programas pretendidamente humorísticos -en un tono ordinario de fiesta de final de curso- funcionan en realidad como propaganda conservadora. Porque la 'coñita cretinizadora' y persistente sobre personajes políticos del color que sea acaba infectando también las instituciones democráticas que estos personajes, con todos sus defectos, representan legítimamente." (Vallès, 2008: 400)

Polònia presenta un formato que podemos encuadrar en el infoentretenimiento, puesto que no solo pretende divertir, sino que basa sus contenidos en la actualidad noticiada de la semana (Ferré Pavia y Gayà, 2009). El infotainment incluye la información entendida como hechos noticiables de actualidad -es decir, aquellos que han sido cubiertos por los géneros tradicionales y que la audiencia informada conoce- $\mathrm{y}$ el entretenimiento, el uso del humor o de la sátira para explicar estos hechos. Este género nace en un contexto global de porosidad entre información y entretenimiento, que abarca tanto la programación como el tratamiento de las noticias. El programa ha demostrado a lo largo de su historia una fuerte vocación por incluir en sus contenidos todas las referencias informativas relevantes, aunque eso significara retrasar el rodaje de sus gags hasta muy poco antes de la emisión del programa.

En Polònia se opina a través del entretenimiento humorístico y la máscara, aplicando a los políticos y a la realidad política los espejos deformantes de la sátira con la carga de opinión que se eso conlleva. El programa no solo informa sino que, sobre todo, interpreta las noticias que han sido tratadas por los medios, es decir, la audiencia ya tiene un conocimiento previo a través de los media. 
Polònia se inscribe en una larga tradición que va desde el británico Spitting Image o el francés Les Guignols de l'Info hasta el argentino Gran Cuñado ${ }^{4}$ pasando por el israelí Eretz Nehederet o el vasco Vaya Semanita. A diferencia de los dos primeros, pero en consonancia con los tres últimos, Polònia usa actores caracterizados para sus gags, lo que contribuye a aproximar realidad y ficción, algo frecuentemente subrayado por los críticos del programa, quienes denuncian que la audiencia puede tener dificultades para distinguir entre una de otra.

El periodismo informativo convencional selecciona y jerarquiza hechos para convertirlos en relato periodístico. Polònia parte de dicha narración periodística para construir lo que llamaremos un relato de segunda generación o metarrelato. Al seleccionar y jerarquizar al modo de los espacios informativos convencionales, el programa construye y presenta también su propia agenda: aquello a lo que, según su parecer, vale la pena atender y comentar.

En el debate está si esta agenda polonizada -la establecida a partir de la agenda mediática- puede adquirir la fuerza suficiente para influir en el imaginario o crear un pseudoentorno (Lippmann, 1922/1949) paralelo a los espacios informativos convencionales.

El programa, atendiendo a las reglas de la sátira y la caricatura, subraya y exagera en cada uno de los personajes determinados rasgos identificativos. Somete a los políticos y a sus actuaciones a una operación de priming o encuadramiento. ¿Qué es lo que da intensidad al framing de Polònia? El programa pone al acento en la humanización de las figuras políticas y en el conflicto, real o mediático, en el que están implicadas. Así el espectador puede colarse en las bambalinas de la política. Tiene la sensación de observar a los políticos y lo que hacen sin fingimiento, sin máscara. El programa estaría desenmascarando gracias a la máscara de la sátira.

El espacio de Televisió de Catalunya hace que los espectadores sientan que observan desde dentro aquello que los espacios informativos le han contado previamente, convirtiéndose así en una suerte de voyeurs. Polònia se beneficia del efecto realidad o de la presunción de verdad que va unida a la imagen, algo favorecido por la aparición de actores caracterizados como los personajes políticos a quienes imitan y no, por ejemplo, de muñecos al modo de Spitting Image o Les Guignols de l'Info.

Hay que tener en cuenta también que, al no ser Polònia un programa de información política convencional, es muy posible que el espectador se relacione con él sin las prevenciones, la desconfianza y los mecanismos de defensa que sí podrían activarse ante espacios de información política seria.

Sucede, y no solo como anécdota, que cuando determinados políticos parodiados en el programa aparecen en las noticias audiovisuales, el público ve y oye a sus dobles de Polònia. Este efecto se vería galvanizado por la aparición periódica de los lí-

${ }^{4}$ El expresidente de Uruguay Julio María Sanguinetti consideró Gran Cuñado un "arma terrible" capaz de modificar los hábitos de los ciudadanos y sustituir el debate político. Según él, "nadie imaginaba que la imagen, la sola imagen, podía llegar a sustituirla [a la palabra], y mucho menos en el debate político, entablado en un juego de emociones, risas, ridículos, en que la razón es la gran ausente". 
deres políticos junto a los personajes de Polònia (Sintes, 2010). Este tipo de cameos se produjeron por última vez antes de la redacción de este artículo con motivo de las elecciones legislativas españolas de 20 de noviembre de 2011.

Sobre los cameos previos a estos comicios, reflexionaba quien fuera estrecho colaborador de Pasqual Maragall y José Montilla en sus etapas como presidentes del gobierno catalán, Jaume Badia. Quien fue director del departamento de Análisis y Prospectiva de la Generalitat de Catalunya interpelaba a los dirigentes políticos que se habían prestado a aparecer en el programa y lanzaba una larga batería de ásperas preguntas, entre ellas la siguiente:

“¿No saben que, haciendo el juego al guión del Polònia, corren el riesgo de que los ciudadanos piensen que la parodia que presenta a la clase política como infantil, vanidosa, border-line, superficial, cargada de prejuicios, envidias y fanatismos dogmáticos, es más realista de lo que parece?" (Badia, 2011:8)

Toni Soler, director del programa, está de acuerdo que se puede crear un efecto realidad: "A veces la parodia es tan fuerte que puede eclipsar al personaje real". Soler añade que no es deseable que la audiencia "crea que el presidente de Catalunya es Sergi Mas [el actor encargado de interpretar el personaje de José Montilla]". "Tal vez efectivamente marcamos la opinión de la gente en un sentido u otro", comenta. Según Soler, no hay que buscar el problema en el éxito de Polònia, sino en la falta de compensación y equilibrio de programas políticos convencionales: "El problema existe. Sin embargo, alguien piensa que, si nos cargamos la sátira, florecerán la política y el pensamiento serio? A mi esto sí que me parece un buen chiste"s. Soler, al igual que las dos otras almas del programa, Manel Lucas y Queco Novell, proceden profesionalmente del campo del periodismo político.

El Consell del Audiovisual de Catalunya (CAC), órgano regulador del audiovisual catalán, constataba en el 2007 el déficit de programas de debate político:

"El factor determinante no es el éxito de Polònia, que se inscribe en la tradición de humor político de otras televisiones públicas europeas, sino el déficit de programas de debate político y participación cívica que hacen que Polònia se convierta en el grueso de la oferta en este tipo de programación y no en su complemento. Todo lo cual acaba por alimentar una cierta banalización de la política democrática." (Consell de l'Audiovisual, 2007)

José Luis Valhondo apunta que el público objetivo de la infosátira ha crecido en un contexto de escepticismo respecto a las instituciones de gobierno y este género se limita a hacerse eco de la desconfianza a través de la ridiculización. Después de analizar diferentes programas de este género, el autor concluye: "Es muy probable que la infosátira analizada promoviese una idea desmovilizadora de la política". (Valhondo, 2007: 69)

${ }^{5}$ Declaraciones de Toni Soler al programa Disculpin les molèsties. La política a través de la tele. De "La Clave" a "Polònia", emitido el 8 de abril de 2010 por TV3. 


\section{Objetivos de investigación}

- Objetivo 1.- La imagen de la clase política

A través de diferentes técnicas se ha investigado si el programa tiene una función divulgativa de las figuras políticas, si se establece como un canal de humanización de la imagen de estos líderes y si se pueden generar cambios de actitud ante estos políticos, como mayor simpatía o rechazo. La investigación contrasta la percepción de la ciudadanía y la de los spin-doctors de los partidos. El estudio plantea a los asesores cómo afecta a la imagen de sus líderes aparecer en el programa.

- Objetivo 2.- Retrato de la vida política

Los personajes de Polònia constituyen una galería que se interrelaciona. Sus acciones pueden divulgar una u otra visión sobre qué significa el llamado juego político $y$ la vida política que representan los partidos. La investigación formula si el conflicto que retrata el programa se percibe como más o menos fiel al que muestra la información, tanto por parte de los televidentes como de los partidos.

- Objetivo 3.- Interés por la política y participación

Las investigaciones divergen sobre si el efecto del consumo televisivo frena o incentiva la participación ciudadana y política de los espectadores. Este estudio ahonda en si un programa de sátira suscita un mayor o menor interés por la política, provoca cambios de opinión entre la audiencia y puede afectar a una cierta movilización electoral. Abunda, además, en si los asesores de comunicación consideran que el programa afecta a la agenda política.

\section{Diseño metodológico}

Hemos aplicado las siguientes herramientas de investigación social: una encuesta de tipo cuestionario, un grupo de discusión y entrevistas focalizadas a los asesores de comunicación de los partidos.

\subsection{La encuesta aleatoria}

La encuesta se llevó a cabo en Barcelona y en su área metropolitana en verano del 2008. Contestaron a la encuesta 1.241 personas. La muestra, una vez filtrada, se configuró con un corpus de 987 personas, al eliminar las que coincidían demasiado en edad o en el perfil profesional, lo que hubiera creado un sesgo social en la muestra. Representando a la población total, el margen de error no superaría el 3\%.

Por sexo, la muestra de la encuesta está compuesta por 476 mujeres y 512 hombres. Por edades, están representadas desde los 17 a los 88 años (excepto los de 86 y 87 años). El cuestionario se planteó en 13 preguntas, de las que 10 fueron de respuesta cerrada y 3 , de abierta. A través del programa estadístico SPSS se establecieron 46 tablas de análisis con resultados cruzados.

\subsection{Grupo de discusión}

El trabajo con el grupo de discusión ha permitido profundizar en los valores sobre la política y sobre la incidencia que este tipo de programa puede tener en la participación 
cívica y electoral. Se compuso de 6 profesionales ${ }^{6}$ y la conversación se desarrolló entorno a 5 preguntas motor. A partir de la trascripción de las conversaciones, se creó un sistema de indicadores para evaluarlas según los objetivos planteados.

\subsection{Entrevistas focalizadas}

Para abordar las percepciones de la clase política se citó a los responsables o exresponsables de comunicación de las 6 principales fuerzas que concurrían a las elecciones autonómicas catalanas de 2010: David Madí, José Zaragoza, Eladio Jareño, Xavier Vendrell, Marc Rius y Jordi Cañas. Las entrevistas focalizadas tuvieron lugar entre los meses de mayo y julio de 2011 y fueron un total de 6 encuentros individuales con una duración de entre 45 y 90 minutos. El cuestionario constaba de 11 preguntas y se evaluó según el análisis de contenido.

\section{Resultados de investigación}

En este artículo los resultados se presentan ordenados según los objetivos de investigación. En cada uno reseñaremos datos obtenidos a través de las diversas técnicas metodológicas aplicadas: encuesta, grupo de discusión y entrevistas.

Según los resultados de la encuesta, el perfil mayoritario del televidente de Polònia es el de una persona que se considera a sí misma informada (en un 76,2\%), mayor de 60 años y para la que los contenidos del programa tienen un gran impacto de recuerdo (73,2\%). Polònia aparece ante su audiencia como una herramienta complementaria de información. Los que consideran que el programa informa en mayor o menor medida ascienden a un $83,3 \%$ del total.

También es interesante tener en cuenta que un 58,6\% de los encuestados afirman que el programa de sátira tiene mayor libertad informativa que un noticiero al uso.

\subsection{La imagen de las figuras políticas}

\subsubsection{Divulgación de las figuras políticas}

La encuesta de calle muestra que el programa ayuda a conocer a las figuras políticas. Un $83,5 \%$ de los encuestados conocen y citan el cargo de la entonces vicepresidenta del Gobierno. Una cifra tan elevada indica, pues, la capacidad del programa para aumentar el conocimiento público de las figuras políticas. Además, si tenemos en cuenta la frecuencia de consumo del programa, se confirma que entre los que ven más asiduamente Polònia, este conocimiento aumenta al 87,9\%.

En el análisis del grupo de discusión, Polònia aparece como un canal divulgativo de las figuras políticas que deja al margen -y esto es expresado como una queja-otros aspectos de la vida política. Se establece una clara distinción entre vida política y líderes de los partidos. Concluyen que el programa humaniza a los políticos y los acerca a la ciudadanía.

Hay acuerdo en que el programa no es "ecuánime" en el tratamiento que se hace de los políticos. Se afirma que no todas las figuras políticas son tratadas con la misma

${ }^{6}$ Se trata de 6 personas con estos perfiles profesionales: un taxista, un pintor, un maestro jubilado, un estudiante panameño de posgrado en paro, un cartero y un carpintero. Se celebró en octubre de 2008. 
"amabilidad". La parodia puede incidir en la actitud que tienen hacia la persona real. Para el grupo, aparecer en el programa es beneficioso para la popularidad de los políticos aunque temen el tipo de caricatura que se haga. La caricaturización también aparece como un refuerzo del desencanto político que ya alberga una parte de la ciudadanía.

Entre los responsables de comunicación de los partidos existe una rotunda unanimidad en cuanto a que el programa contribuye notablemente al mayor conocimiento de las figuras políticas. También hay coincidencia en que Polònia acerca a los políticos a sectores de la población que, de otra manera, no conectarían con sus representantes o con los dirigentes de los partidos. Así, por ejemplo, José Zaragoza, secretario de organización y finanzas del PSC-PSOE, cargo que incluye la comunicación entre sus atribuciones, opina que el programa "acerca la política a un segmento de la sociedad que ni la escucharía ni la vería". Varios de los entrevistados resaltan que "naturalmente" existe una distorsión de las figuras políticas aunque admiten que está construida a partir de una base real.

\subsubsection{Humanización de las figuras políticas}

Las conclusiones del grupo de discusión también muestran que este formato humaniza a los políticos, ya que los presenta de forma distendida y dentro de un marco emotivo y de relaciones personales que generalmente es excluido de la información estricta. Llegan al acuerdo de que acerca las figuras políticas a la audiencia y puede generar distintas sensibilidades dependiendo de cómo se represente a los líderes.

Los especialistas en comunicación política coinciden en que el programa de TV3 influye en la percepción que tienen los telespectadores de los políticos, bien en clave positiva o en clave negativa. Igualmente muestran un notable acuerdo, aunque no tan amplio como en el caso del grupo de discusión, sobre la capacidad del programa de humanizar y mostrar más próximos y simpáticos, o más distantes y poco agradables, a los políticos parodiados. En este sentido, puede ser ilustrativa la reflexión de Eladio Jareño, coordinador de presidencia y comunicación del PP de Cataluña: "Existen personas a quien posiblemente ha humanizado, los ha acercado al espectador y al público. En otros casos, les ha hecho mucho daño".

\subsubsection{Cambios de actitud en la audiencia}

Entre los encuestados existe una clara división entre los que afirman que el programa les genera simpatía o rechazo hacia las figuras representadas $(49,4 \%)$ y los que dicen que no $(50,6 \%)$. Así, la mitad de los encuestados aceptan cambios emotivos en su día a día provocados por la parodia.

Hay que tener en cuenta que esta división casi al 50\% de los que admiten que el programa genera cambios de actitud se produce independientemente de la valoración de la parodia. Tanto si tomamos como muestra a los que consideran que sí existe parecido entre personas y personajes $(91,2 \%)$ como al resto, estos se muestran divididos de la misma manera.

Los participantes del grupo de discusión apuntan que solo una parte del público conoce las características de este formato televisivo, mientras que la otra puede con- 
fundir realidad y ficción y entender los atributos de los personajes como reales. En el focus group se afirma que la infosátira no genera falsedades, ya que el programa se encarga de hacer evidente que es una parodia. Sostienen que la caricaturización de las figuras políticas puede hacer que parte de la audiencia se desinterese por la política. Esto sucedería entre una ciudadanía previamente desmotivada y que desconfía de las figuras políticas.

A diferencia tanto de la encuesta como del grupo de discusión, los responsables de comunicación de los partidos se muestran de acuerdo en que el programa de parodia política tiene influencia en la percepción del espectador sobre las figuras políticas. Alguno de ellos señala, además, que el estereotipo que el programa fija puede convertirse en un lastre, pues raramente se pueda modificar.

Donde sí se producen claras discrepancias entre los responsables de comunicación es en el asunto del parecido entre los personajes de Polònia y los dirigentes políticos parodiados. Hay opiniones para todos los gustos. José Zaragoza (PSC-PSOE) considera que "no se parecen en nada; es una realidad esperpéntica". Otros, en cambio, apuntan que en algunos casos el parecido es "grande" o "notable". Marc Rius, secretario de comunicación de ICV-EUiA, es de los que creen que la parodia retrata con bastante acierto a los políticos: "Está bastante bien cogido el talante y el discurso político, evidentemente haciendo de ello caricatura. Otro problema es si la gente tiene capacidad suficiente para distinguir entre la realidad y el personaje".

Sobre esta distorsión, David Madí, exsecretario de comunicación y estrategia de Convergència Democràtica de Catalunya (CDC), introduce una salvedad: "Depende de la fase de construcción del personaje. Cuanto más consolidado esté un liderazgo político, menos lo contamina Polònia, más se disocia el personaje de la realidad”.

\subsection{Retrato de la vida política}

En cuanto a la percepción del conflicto en la vida política, el 50,9\% del total de encuestados creen que los políticos no se enfrentan de la forma en que lo muestra el programa. ${ }^{7}$ El $49,1 \%$ opina que sí que lo hacen o incluso que se pelean aún más $(22,2 \%)$. Este dato refuerza la visión de que, en algunos aspectos, la audiencia del programa está muy dividida en cuanto a la percepción de sus efectos.

La gente encuestada de más edad es la que tiene una visión de la vida política más conflictiva $(61,1 \%)$. Estos perciben un margen más amplio para la parodia, teniendo en cuenta que consideran que la pelea política real es aún mayor.

Con respecto a los resultados del focus group, los participantes también consideran que hay más margen para la sátira y resaltan el valor paródico del programa. Afirman que el programa ayuda a calmar la crispación política a través del humor. De todas maneras, están muy divididos entre los que creen que el programa llega a distorsionar la percepción de la audiencia sobre la vida política representada y los que, en cambio, afirman que Polònia analiza las relaciones "verdaderas" entre políticos aunque en clave de humor.

7 En el estudio se muestra que no son los consumidores habituales del programa los que perciben la vida política como más conflictiva: del grupo que considera que se pelean "aún más” de lo que muestra Polònia (22,2\%), sólo son consumidores habituales un 35,6\%. 
El grupo alerta de la capacidad que tiene el programa para generar estereotipos, pero en este aspecto no le atribuyen intencionalidad. Lo describen como un programa de humor inteligente que no genera "falsedades". Y reclaman que un programa de sátira política "es necesario en la parrilla". Aparece, de nuevo, la desconfianza hacia los políticos, ya que se habla de su "hipocresía".

En el caso de los responsables de comunicación, cuatro de los seis entrevistados consideran que efectivamente lo que el espectador ve en el programa se parece a la realidad política. Los especialistas discrepantes son José Zaragoza (PSC-PSOE) y Jordi Cañas, secretario de comunicación de Ciutadans.

En cuanto a la explotación del conflicto por parte del programa, Eladio Jareño (PPC) apunta: "No creo que lo que sucede en la política sea peor que lo que sucede en la vida de cualquiera". Añade un elemento de distinción: "La escenificación de la política sí que se parece más a lo que es el programa, pero no la relación real entre las personas". Según Jareño, esto se debe a que los propios políticos se ven obligados a subrayar la discrepancia; pues para los medios si no hay polémica, tensión o crispación "parece que no es noticia".

Xavier Vendrell, exvicesecretario general de coordinación interna y acción electoral de ERC y encargado de la campaña de las elecciones autonómicas de 2010, comparte la misma opinión: "No es noticia que haya acuerdo". Vendrell manifiesta que el programa exagera o que no refleja con fidelidad lo que ocurre. "Los políticos, en todo caso, se pelean de forma diferente", afirma.

Jordi Cañas (Ciutadans) añade que la realidad que se muestra en Polònia presenta "un sesgo a nivel identitario [catalán]" y concluye que se trata de un espacio que hace caricatura política, pero que al mismo tiempo tiene intencionalidad, "una estrategia política". En este aspecto abunda Eladio Jareño (PPC): "La perspectiva del programa no es neutra, sino totalmente intencionada". Y añade: "Parten de la opinión publicada, de los informativos de la casa [Televisió de Catalunya], de la línea de la casa, pero eso no siempre es exactamente lo que sucede en Cataluña".

\subsection{Interés por la política y participación}

\subsubsection{Generación de interés por la política ${ }^{8}$}

En el grupo de discusión se concluye que Polònia ayuda a conocer los asuntos políticos siempre que se tenga una información previa. La relación que se establece con la información es de dependencia, es decir, que es necesario estar informado para entender los contenidos del programa.

Se afirma que el programa no genera ni debate ni discusión entre los espectadores. Se marca una división muy clara entre estar "más informado" y estar "más pendiente". El grupo acuerda que Polònia aporta información, pero ésta no se traduce en más atención a la política. Algunos participantes defienden que, tal y como se presenta, "la información" puede alejar de la política a los espectadores ya desconfiados. La

${ }^{8}$ En la encuesta no se abordó el tema del interés, ya que esta hacía énfasis en los efectos emotivos y actitudinales y no en los políticos, que se trataron con detalle en el grupo de discusión. 
desafección previa se reforzaría con la sátira y el humor con que se presentan los representantes políticos parodiados.

Los spin-doctors se muestran claramente divididos en lo que se refiere a si el programa genera un mayor interés por la política. Entre los que consideran que no, está David Madí (CDC), quien piensa que el interés que pueda despertar es "superficial". Jordi Cañas (Ciutadans) cree que el espacio televisivo no promueve más interés por la política aunque la haga más próxima: "Es una de las pocas formas para que los ciudadanos se acerquen voluntariamente al escenario político, pero más como una arena de circo romano y no tanto como un ágora de debate".

Marc Rius (IC-EUiA) considera que el programa sí puede desembocar en un mayor interés por la política: "En personas que no tienen una gran cantidad de instrumentos para pensar sobre la política, sí que puede ser un instrumento de aproximación a esta y, a partir de aquí, generar interés".

\subsubsection{Capacidad para generar cambios de opinión}

$\mathrm{Ni}$ en la encuesta ni en el grupo de discusión se revela que un programa como este pueda influir en la opinión de los televidentes. Los encuestados niegan en un 90,8\% que les haya hecho cambiar de opinión en algún momento. ${ }^{9}$

Los encuestados que consideran que el programa tiene un gran peso informativo admiten en mayor medida que éste sí les ha suscitado un cambio de criterio $(20,9 \%)$, esto es, aumenta en 10 puntos el porcentaje de encuestados que aceptan este poder.

En el 90,8\% que niega el cambio de opinión se repite la división casi al 50\% entre los que creen que las relaciones entre los políticos no son tan conflictivas como se muestra en Polònia y aquellos que las asumen como un retrato real o incluso suavizado (el 20,2\% creen se pelean "aún más").

Como hemos visto, los responsables de comunicación creen que la forma de caracterizar a sus líderes puede incidir en la percepción que la ciudadanía acabe teniendo de estos. De igual forma, cuando se les pregunta sobre si Polònia puede determinar la opinión del público sobre determinados temas, la gran mayoría responde afirmativamente. El que muestra más dudas es el socialista José Zaragoza, quien considera que el programa televisivo resulta más influyente en la percepción de las personas que en la de los asuntos políticos.

Los responsables de comunicación coinciden al rechazar que el programa haya marcado o pueda marcar la agenda política. Algunos de los entrevistados apuntan que puede contribuir a consolidar un tema determinado. También subrayan la proximidad entre los contenidos del programa y la actualidad más reciente.

\subsubsection{Participación e incidencia electoral del infotainment}

En el grupo de discusión hay unanimidad en que el programa no crea implicación en la vida política. Cuando se debate sobre la afectación electoral de Polònia, esta una-

9 Aunque no se tiene en cuenta en la presentación de este artículo, una encuesta vía web realizada a 987 seguidores del programa arroja, en cambio, otro resultado: entre éstos, sube a un $69,3 \%$ los que de alguna manera aceptan la capacidad del programa como generador de cambios de opinión. 
nimidad se refuerza: coinciden en que no incide ni en la movilización ni en la desmovilización de los televidentes. Alguno de los participantes apunta, en cambio, que puede generar esta movilización a largo plazo.

Aparece como afirmación que la imagen que da Polònia de los políticos y de las relaciones entre ellos puede hacer que la gente que ya no participa electoralmente encuentre en el programa argumentos para reafirmarse en este alejamiento. Vemos, otra vez, como en el grupo las actitudes de recelo hacia la política matizan muchas de las opiniones compartidas.

El humor puede funcionar como catarsis, pero la caricaturización de las figuras políticas y de las relaciones que estas establecen pueden ser un freno o reafirmar el desencanto de una parte de la ciudadanía.

En cambio, los responsables políticos sí están de acuerdo en que el programa televisivo puede tener efectos en los resultados electorales, incluida la abstención. Prácticamente todos coinciden en señalar que, puesto que forma parte del relato político y atrae a una gran audiencia, forzosamente algún grado de influencia ha de tener $\mathrm{Po}$ lònia. El efecto consistiría, sobre todo, en reforzar las dinámicas electorales ya existentes.

Sin embargo, no hay unanimidad entre los spin-doctors sobre si Polònia puede contribuir al alejamiento ciudadano de la política. David Madí (CDC) considera que "Polònia puede generar desafección, pero también puede movilizar, según las circunstancias". Otros, como Eladio Jareño (PPC), señalan que el programa "no contribuye, evidentemente, al crédito de la política y al prestigio de los políticos". En su opinión, tendería más a alimentar la abstención y el voto en blanco que no el voto hacia un determinado partido. Jordi Cañas (Ciutadans), por su parte, subraya que la imagen del anterior Gobierno (PSC-ERC-ICV) estuvo profundamente influida por el programa: "Polònia satura el enfrentamiento, y la gente, cuando ve el Telenotícies (los telediarios de TV3), acaba asociándolos".

Al ser preguntados por qué aconsejaron o desaconsejaron al líder de su partido que participara en el programa, las respuestas más frecuentes son tres: a) porque es bueno mostrar y fomentar el sentido del humor, también sobre la política; b) porque podría ser beneficioso en términos político-electorales, y c) porque el resto de líderes accedía a participar.

\section{Conclusiones}

Polònia ha dado lugar a una recurrente polémica sobre su influencia en la actitud de los ciudadanos hacia la política y, también, sobre qué líderes o partidos son los que se verían más beneficiados o perjudicados por el tratamiento que el programa realiza de la actualidad política. Nuestra investigación se propuso profundizar y aportar luz al debate pulsando la opinión de los ciudadanos, por una parte, y de destacados responsables de comunicación de las principales formaciones políticas catalanas, por otra.

En cuanto al primer objetivo de la investigación, centrado en la imagen de la clase política, tanto ciudadanos como expertos resaltan el poder del programa para producir un aumento del conocimiento público de las figuras políticas. Además, su formato lo convierte en más atractivo para aquellos ciudadanos poco o nada familiarizados 
con la actualidad política. Unos y otros coinciden al apuntar que el programa tiende a humanizar y hacer más próximos a los líderes parodiados. Este el único punto en que ciudadanos y spin-doctors manifiestan un acuerdo: Polonia acerca a los políticos a sus posibles votantes.

El programa informa, aunque esta información se convierte en relevante y fértil siempre que el espectador atesore ya un nivel de conocimiento de la política que le permita descodificarla e interpretarla adecuadamente. Cabe destacar que casi un $60 \%$ de los encuestados consideran que un espacio de este tipo tiene más margen para informar que programas de noticias ortodoxos.

Sobre la generación de emociones y la posibilidad de que se favorezcan los cambios de actitud, expresados en simpatías o antipatías, los expertos señalan que el metarrelato de Polònia puede originarlos. Hay coincidencia en que la distorsión inseparable de la caricaturización y la parodia tendrá mayores efectos en función del mayor o menor conocimiento previo de las figuras y asuntos políticos que tenga el espectador. Hay que tener en cuenta que los seguidores de Polònia encuestados se consideran un público informado, que consume medios informativos diariamente en un $76,2 \%$.

Los ciudadanos creen que hay un fuerte parecido entre los dirigentes políticos y sus imitaciones en el programa, algo sobre lo que los spin-doctors se expresan con mayor escepticismo.

Una constante apreciada en las valoraciones y opiniones de los ciudadanos es que éstos suelen ser críticos con los líderes políticos. Esto cambia radicalmente cuando quien habla son los asesores o responsables de comunicación de los partidos: ellos tienden a dirigir sistemáticamente sus reproches hacia los medios de comunicación y los periodistas.

Sobre cómo retrata Polònia la vida política, nuestro segundo objetivo, hay una división entre los que consideran que el programa exagera la conflictividad política y los que piensan que la retrata o incluso la suaviza. En este caso, spin-doctors y una parte de la ciudadanía coinciden en que el infotainment puede explotar el valor noticia del conflicto como sucede también en la vida real. Los asesores subrayan que, a veces, los líderes políticos tienden a exagerar sus diferencias reales con el fin de obtener la atención de los periodistas y ganar espacio en los medios de comunicación.

En relación a nuestro tercer objetivo, centrado en el interés por la política y la participación, los encuestados no están de acuerdo en que Polònia genere mayor interés por la política. La ciudadanía considera el programa incapaz de motivar en ellos cambios de opinión significativos en relación a los políticos y a los asuntos de la política, pero los responsables de comunicación son rotundos al afirmar que sí los produce. Hay entre estos últimos quien apunta que la capacidad de influir de los media sería especialmente visible cuando el programa recoge, acentúa y potencia una tendencia, un estado de opinión, ya existente en la propia sociedad.

¿Piensan lo mismo ciudadanos y políticos sobre la sátira de Polònia? Es la pregunta que impulsa este artículo. Las herramientas de investigación muestran que el peso de este género en lo que se refiere a su capacidad divulgativa es efectivo. Es interesante destacar que los spin-doctors son más proclives a percibir que la vida política es con- 
flictiva, ya que el retrato que hace el programa de esta les parece fiel. La ciudadanía, en cambio, se muestra dividida. Los ciudadanos de la muestra se niegan a reconocer que el programa pueda aumentar su interés por la política, generar un cambio de opinión o incidir en el voto o afectar a la abstención. Los asesores de comunicación de los partidos, por su parte, piensan de manera unánime todo lo contrario.

Son justamente las diferencias de esta naturaleza entre ciudadanos y asesores de comunicación lo que destaca en el conjunto de nuestra investigación. La diversidad radica en la autopercepción que de sí mismo tiene el ciudadano, quien se considera perfectamente capaz de separar la realidad de la sátira que presenta el programa.

En el caso de la ciudadanía, nuestros resultados se acercan a las propuestas de Delli Carpini (2001), Jones (2004), Moy, Xenos y Hess (2005) y Thussu (2007). Los ciudadanos se consideran a sí mismos un público sofisticado, con capacidad de leer la ficción del género, distinguirla de la realidad y mantenerse al margen de la influencia. Los asesores de comunicación manifiestan sus reservas sobre la capacidad ciudadana de blindarse ante un género interpretativo.

Los expertos en comunicación entrevistados comparten la idea de que Polònia sí incide e influye en determinados aspectos de la relación de los ciudadanos con los políticos y la política. Según ellos, que se trate de un programa de entretenimiento y de humor no le restaría capacidad de influencia sobre los espectadores. Apuntan que es posible que, por las características del programa, la audiencia pueda mantener una actitud menos vigilante y defensiva y esto permita a Polonia trasladar al ciudadano sus puntos de vista y actitudes y que lo haga con mayor eficacia.

La ciudadanía consume un programa como este con sentido del humor y de manera complementaria a la información. La clase política, en cambio, reconoce y se muestra preocupada por los cambios de opinión y la capacidad movilizadora que un programa de sátira política como este puede generar. Son conscientes que el conflicto es noticia y tienen herramientas para gestionar cómo aparecerá este en el relato informativo. Reconocen en el metarrelato de Polònia una fuerza que incluso puede afectar el voto.

Por tanto, no se puede acusar al formato de fomentar la abstención o bien mover a una determinada elección electoral con datos que muestren discrepancias por sectores. La sátira sigue siendo una incógnita: los asesores aconsejan a sus candidatos aparecer en el programa aunque, según los resultados de la investigación, no se pongan de acuerdo si esto les beneficia de alguna manera. La ciudadanía, en cambio, se mantiene al margen de este debate: dice tener herramientas para percibir de manera crítica la parodia y el humor.

\section{Referencias bibliográficas}

BADIA, Jaume (2011): “Polònia, cómics y títeres”. El Periódico de Catalunya, 1 de noviembre, p. 8.

BAYM, Geoffrey y JONES, Jeffrey (2012): "News Parody in Global Perspective: Politics, Power, and Resistance, Popular Communication". The International Journal of Media and Culture, vol. 10. núm. 1-2, pp.2-13. 
BRANTS, Kees (1998): “Who's Afraid of Infotainment?”. European Journal of Communication, vol. 13 (3), pp.315-336.

CAPPELLA, Joseph N. y JAMIESON, Kathleen H. (1997): Spiral of Cynicism. The Press and the Public Good. Nueva York/Oxford, Oxford University Press.

CONSELL DE L'AUDIOVISUAL DE CATALUNYA (2007): "Informe específic de pluralisme durant la campanya de les eleccions municipals 2007 (del 11 al 25 de maig). Valoració del Consell Audiovisual de Catalunya (aprovada en sessió de 6 de juny de 2007)", de 6 de junio de 2007. http:/www.cac.cat/pfw_files/cma/actuacions/Continguts/Acord_Valoraci_municipals_2007_2_.pdf [publicada 2007, acceso 15 de marzo de 2012]

DELLI CARPINI, Michael X. y WILIAMS, Bruce A. (2001): "Let us infotain you: Politics in the new media environment" en BENNET, W.L. y ENTMAN, R.M. (eds.): Mediated politics: Communication in the future of democracy. Cambridge, MA, Cambridge University Press, pp.160-181.

FERRÉ PAVIA, Carme y GAYÀ, Catalina (2009): "Infoentreteniment i percepció ciutadana de la política: el cas de Polònia", proyecto de investigación financiado por el Consell de l'Audiovisual de Catalunya (CAC), Barcelona.

JONES, Jeffrey (2004): Entertaining Politics: New Political Television and Civic Culture. Lanham, Rowman \& Littlefield.

LANG, Kurt y LANG, Gladys (1966): "The Mass Media and Voting”, en BERELSON, B. y JANOWITZ, M.: Reader in Public Opinion and Communication. New York, Free Press.

LIPPMANN, Walter (2003): La opinión pública. Barcelona, Langre [Public Opinion, 1922, renovado el 1949 por el autor].

LLOYD, John (2004): What the Media are Doing to Our Politics. London, Constable.

MARTÍNEZ SOLANA, Yolanda (2006): "El referente como definición de diferentes formas de comunicación social", en Estudidos sobre el Mensaje Periodístico, vol. 12, pp.171-183. Madrid, Servicio de Publicaciones de la Universidad Complutense.

MC NAIR, Brian (2006): Cultural Chaos: Journalism, News and Power in a Globalized World. London, Routledge.

MOY, Patricia, XENOS, Michael A. y HESS, Verena K. (2005): "Communication and Citizenship: Mapping the Political Effects of Infotainment". Mass Communication \& Society, 8 (2), pp.111-131.

NORRIS, Pippa (2000): A Virtuous Circle. Political Communications in Postindustrial Societies. Cambridge, Cambridge University Press.

PATTERSON, Thomas E. (1993): Out of order. New York, A. Knopf.

POSTMAN, Neill (1985): Amusing Ourselves to Death. Public Discourse in the Age of Show Business. New York, Viking. 
PUTMAN, Robert D. (2000): Bowling Alone: The Collapse and Revival of American community. New York, Simon \& Schuster.

ROBINSON, Michael J. (1976): "Public Affairs Television and the Growth of Political Malaise: The Case of «The Selling of the Pentagon»". The American Political Science Review, 70 (2), pp. 409-432.

RODRÍGUEZ VIRGILI, Jordi; LÓPEZ-ESCOBAR, Esteban; y TOLSA, Antonio (2011): "La percepción pública de los políticos, los partidos y la política, y uso de medios de comunicación", en Comunicación y Sociedad, vol. XXIV, núm. 2, pp.740.

SABATO, Larry J. (1991): Feeding Frenzy. Attack Journalism and American Politics. New York/Toronto, Free Press/Maxwell MacMillan.

SANGUINETTI, Julio M. (2009): “La comedia del poder”. El Pais, 13 de junio, p. 31

SCHUDSON, Michael (1995): The Power of News. Cambridge (Massachusetts), Harvard University Press.

SINTES, Marçal (2010): "Política i política 'polonitzada'”. Trípodos, núm. 27, Barcelona.

THUSSU, Daya K. (2007): News as entertainment. The rise of global infotainment. London, Sage.

VALLÈS, Josep M. (2008): Una agenda imperfecta: amb Maragall i el projecte del canvi. Barcelona, Edicions 62.

VALHONDO, José L. (2007): “Infosátira y democratización del espacio televisivo: el caso español”. Quaderns del CAC, núm. 27, pp. 63-71.

\section{Anexo: gráficos}


Gráfico 1. Tabla de porcentajes de los totales de la encuesta

1. Participantes por sexos

\begin{tabular}{l|l|}
\hline Mujeres & 48,2 \\
Hombres & 51,8
\end{tabular}

2. Participantes por edades

\begin{tabular}{|l|l|}
\hline 17-25 años & 5,1 \\
26-48 años & 21,1 \\
49-64 años & 44,7 \\
65-87 años & 21,4 \\
88- años & 7,8
\end{tabular}

\section{Frecuencia de consumo del programa}

\begin{tabular}{l|l|}
\hline Habitual & 40,2 \\
Ocasional & 59,8
\end{tabular}

4. Frecuencia de consumo informativo

\begin{tabular}{l|l|}
\hline $2 \mathrm{x}$ & 7,8 \\
semana & 76,2 \\
Diario & 14,2 \\
Ocasional & 1,8 \\
Nunca & 1,
\end{tabular}

5. Capacidad informativa del programa

\begin{tabular}{l|l|}
\hline Complementa & 43,5 \\
Alta & 7,9 \\
Baja & 39,8 \\
Nula & 8,8
\end{tabular}

6. Conocimiento de las figuras políticas

\begin{tabular}{l|l|}
\hline No & 16,5 \\
Sí & 83,5
\end{tabular}

7. Pregunta de comprobación (6): cargo de la figura política

\begin{tabular}{|l|l|}
\hline No & 31,2 \\
Sí & 68,8
\end{tabular}

8. Mayor libertad informativa que los telediarios

\begin{tabular}{|l|l|}
\hline No & 41,4 \\
Sí & 58,6
\end{tabular}

9. Capacidad de recordar y citar contenidos

\begin{tabular}{l|l|}
\hline No & 26,8 \\
Sí & 73,2
\end{tabular}

10. Aceptación del cambio de opinión

\begin{tabular}{l|l|}
\hline No & 90,8 \\
Sí & 9,2
\end{tabular}

11. Semejanza entre personajes y políticos

\begin{tabular}{l|l|}
\hline No & 8,8 \\
Sí & 91,2
\end{tabular}

12. Aceptación de cambios de actitud

\begin{tabular}{|l|l|}
\hline No & 50,6 \\
Sí & 49,4
\end{tabular}

13. Retrato del conflicto político

\begin{tabular}{l|l|}
\hline $\begin{array}{l}\text { Se pelean más } \\
\text { No se pelean } \\
\text { así }\end{array}$ & 22,2 \\
$\begin{array}{l}\text { La pelea es } \\
\text { como se } \\
\text { muestra }\end{array}$ & 27,0 \\
\end{tabular}

Fuente: elaboración propia 
Gráfico 2. Síntesis de resultados del grupo de discusión

\begin{tabular}{|l|l|}
\hline CAMPOS & SíNTESIS DE LAS AFIRMACIONES CON ACUERDO \\
\hline Atención a la política & $\begin{array}{l}\text { Informa distendidamente } \\
\text { Hace falta información previa para su comprensión } \\
\text { Divulga a las figuras políticas } \\
\text { Existe desconfianza hacia la política }\end{array}$ \\
\hline Interés por la política & $\begin{array}{l}\text { No crea ni debate ni discusión } \\
\text { Existe desconfianza hacia la política }\end{array}$ \\
\hline Representación política & Muestra a los políticos, no a la política \\
\hline Imagen de los políticos & Humaniza y acerca a los políticos \\
Beneficia/perjudica políticos
\end{tabular}

Fuente: Elaboración propia 


\section{Gráfico 3. Síntesis de las entrevistas a los responsables de comunicación de los partidos del Parlament}

\begin{tabular}{|c|c|c|c|c|c|c|}
\hline \multirow{2}{*}{ Preguntas } & \multicolumn{6}{|c|}{ Respuestas entrevistados } \\
\hline & D.M. & J.Z. & E.J. & X.V. & M.R. & J.C. \\
\hline \multicolumn{7}{|l|}{$\begin{array}{l}\text { 1.- ¿Cree que Polònia genera más interés por } \\
\text { la política? }\end{array}$} \\
\hline \multicolumn{7}{|l|}{$\begin{array}{l}\text { 2.- ¿Cree que Polònia incrementa el } \\
\text { conocimiento de las figuras políticas? }\end{array}$} \\
\hline \multicolumn{7}{|l|}{$\begin{array}{l}\text { 3.- ¿Cree que lo que los espectadores ven en } \\
\text { Polònia se parece a la realidad política que } \\
\text { ustedes conocen? }\end{array}$} \\
\hline \multicolumn{7}{|l|}{$\begin{array}{l}\text { 4.- ¿Cree que los personajes de Polònia se } \\
\text { asemejan a los políticos parodiados? }\end{array}$} \\
\hline \multicolumn{7}{|l|}{$\begin{array}{l}\text { 5.- ¿Los políticos se pelean tal como el } \\
\text { programa representa? }\end{array}$} \\
\hline \multicolumn{7}{|l|}{$\begin{array}{l}\text { 6.- ¿Cree que Polònia ha marcado la agenda } \\
\text { política en algún momento? }\end{array}$} \\
\hline \multicolumn{7}{|l|}{$\begin{array}{l}\text { 7.- ¿Cree que Polònia puede hacer variar la } \\
\text { opinión sobre determinados temas? }\end{array}$} \\
\hline \multicolumn{7}{|l|}{$\begin{array}{l}\text { 8.- ¿Cree que Polònia influye en la opinión } \\
\text { del espectador sobre los políticos? }\end{array}$} \\
\hline \multicolumn{7}{|l|}{$\begin{array}{l}\text { 9.- ¿Cree que la parodia puede hacer que el } \\
\text { político caiga más o menos simpático? }\end{array}$} \\
\hline \multicolumn{7}{|c|}{$\begin{array}{l}10 .- \text { ¿Cree que Polòia puede tener efectos en } \\
\text { los resultados electorales -incluida la } \\
\text { abstención? }\end{array}$} \\
\hline $\begin{array}{l}\text { 11.- ¿Por qué des/aconsejó que el político que } \\
\text { usted asesora participara en el programa? }\end{array}$ & $\begin{array}{l}\begin{array}{l}\text { Sentido } \\
\text { del } \\
\text { humor }\end{array} \\
\text { Puede } \\
\text { ser útil }\end{array}$ & & \begin{tabular}{|l} 
Sentido \\
del \\
humor
\end{tabular} & $\begin{array}{l}\text { Puede } \\
\text { ser útil }\end{array}$ & $\begin{array}{l}\text { Sentido } \\
\text { del } \\
\text { humor }\end{array}$ & $\begin{array}{l}\text { Puede } \\
\text { ser útil }\end{array}$ \\
\hline
\end{tabular}

Fuente: Elaboración propia

Respuesta negativa

No se define/otros

Respuesta afirmativa 